\title{
Chaotic Home Climate and Antisocial Behavior among Secondary School Adolescents in Aba Education Zone, Nigeria
}

\author{
Dr. (Mrs.) Ngozi Anthonia Amazu \\ Department of Educational Foundations, Guidance and Counselling, \\ University of Uyo, Uyo, Nigeria
}

\begin{abstract}
This study examined the influence of chaotic home climate on the social behaviour of adolescents in Aba Education Zone, Nigeria. The author selected sibling rivalry and parental infighting as independent variables for study. Two research questions and two null hypotheses were formed to guide the study. The study adopted the ex-post facto survey design and collected data from a random sample of 1400 adolescents in the study area. Data for the study was collected with the Domestic Abuse and Antisocial Behaviour Questionnaire with a Cronbach's alpha reliability coefficient of .862. The instrument was designed to generate responses on a 4-point scale of strongly agree to strongly disagree. Analyses of data collected in the study show that adolescents who experienced higher incidents of sibling rivalry at home recorded higher mean scores on the antisocial behaviour scale that their peers who experienced minimal sibling rivalry. It is further shown that adolescents whose parents fought frequently also recorded higher antisocial behaviour mean scores. Thus this study found that both sibling rivalry and parental infighting significantly influenced antisocial behaviour among secondary school adolescents in Aba Education Zone. Recommendations were thus advanced to assist curtail the effect of chaotic home climate on adolescent student behaviour.
\end{abstract}

Keywords: Adolescents; Antisocial Behaviour; Parental Infighting; Educational Psychology

\section{INTRODUCTION}

The society has been worried about the rate of adolescent's antisocial behaviours. Many secondary school students do not show respect to their parents, teachers, and elders. Today, brutal attacks by students on their teachers, parents and fellow students are witnessed. These students damage a lot of school properties including buildings, laboratories, equipment and sometimes teachers' cars. Family studies indicate that adolescent behaviour is usually a reflection of the experiences at home, whether chaotic or stable. Reports of cases where students fight at school and in public places are rampant. These secondary school students may invariably exhibit antisocial behaviour such as violence towards parents, mates, and teachers in school, or resort to alcohol and drug use as a result of domestic abuse they experienced in their homes. These depict low moral upbringing and suggest to the average onlooker that the climate at home is chaotic.

Various variables have been examined in the research literature to ascertain their impact on adolescent behaviour, especially antisocial behaviour. For this study however, the researcher picked interest in variables of chaotic home climate to determine their influence on antisocial behaviour of adolescents in Aba, Nigeria. Sibling rivalry and parental infighting are, based on the researcher's personal observation, believed to be rampant in the study region. As postulated by Donna (2004), sibling rivalry is the jealousy, competition and fighting between brothers and sisters. It is a concern for almost all parents of two or more kids; problems often start right after the birth of the second child. Siblings' rivalry usually continues throughout childhood and can be very frustrating and stressful to parents and as well contribute to social problems.

Children are sensitive from the age of one year to differences in parental treatment (Dunn, 2000). From 18 months and above, siblings can understand family rules and know how to comfort and be kind to each other. By three years old, children have a sophisticated grasp of social rules; can evaluate themselves in relation to their siblings within the family. According to Keinedy-Moore and Katayama (2007), siblings' rivalry often continues throughout childhood and can be very frustrating and stressful to parents and can also influence the children negatively by causing them to be involved in antisocial behaviours in schools.

Adolescents fight for the same reasons younger children fight but they are better equipped physically and intellectually to hurt and be hurt by each other. Physical and emotional changes cause pressures in the teenage years, as do changing relationships with parents and friends. Fighting among siblings as a way to get parental attention may increase the adolescents' involvement in social problems like fighting and bullying others in the school. One study source revealed that the age group ten to fifteen years report the highest level of competition between siblings. Siblings' rivalry can continue into adulthood and siblings' relationships can 
change dramatically over the years. However, Wiehe (1997) said that rivalry often lessens over time. At least eighty percent of siblings over age enjoy close ties.

According to Caspi, McClay, Moffitt, Mill, Martin, and Craig (2002), dismissing siblings' rivalry can cause more harm than good to their studies and bring about a poor academic performance. Most people see aggression between siblings as an unavoidable, normal and ultimately harmless aspect of child development and behavioural problems. Some of these problems may be severe and even precursors to other forms of violence. One of the primary reasons siblings fight is shared space, says Caspi et al, especially if they share a bedroom. Parents and nannies can expect conflicts over toys, remotes, television shows and the need for privacy and the tendencies for them to fight over issues in the school. Researches have determined that the fighting between brothers and sisters is filled with physical and psychological aggression which traumatizes and leads to depression, anxiety and anger. More than 3,500 children under the age of 17 were participants in the study entitled the "National Survey of children's Exposure to Violence". The centre for Disease Control and Prevention (DCP) in conjunction with the Department of Justice (DJ) and Office of Juvenile Justice and Delinquency Prevention (OJJDP) commissioned the research that began the dialogue to blame parents for their child's inability to cope with competition in homes and schools as well. It was found that $32 \%$ of children surveyed reported aggressive behaviour from a sibling which caused them anxiety and distress.

Denilson, (2002) viewed that what damage children emotionally are bitterness, long-lasting, on-going conflict between parents, whether the parents live together or not. The longer the parental conflict continues, and the greater the tension between the parents, the more likelihood that psychological difficulties will result for the children. Such psychological problems include: emotional and behavioural problems, anxiety, depression, sleeping in the class, low self-esteem, fighting other students in the school and a number of other difficulties. He further explains that chronic parental conflicts create a climate of tension, chaos, disruption and unpredictability in the family environment that is meant to be safe secured and comfortable. Children feel anxious, frightened, and helpless when they see their parents fight. They cannot get close to their parents for academic work as a result of the tension in the family. They may worry about their own safety and their parents' safety too. However, Howards (2003) found that children's imaginations are powerful and they may imagine harm coming to themselves or to one of their family members. If parents are still together, there is also worry about divorce and the family being split up.

Purpose of the Study: The main purpose of the study was to determine the influence of chaotic home climate on antisocial behaviour among secondary school students in Aba, Nigeria. Specifically, the study sought to:

1. Find out the influence of siblings rivalry on antisocial behaviour among secondary school students.

2. Find out the influence of parental in-fighting on antisocial behaviour among secondary school students.

Research Questions: The following research questions were answered in the study:

1. What is the influence of siblings' rivalry on antisocial behaviour among secondary school students?

2. What is the influence of parental in-fighting on antisocial behaviour among secondary school students?

Null Hypotheses: The following research hypotheses were tested in the study at 0.05 level of significance: $\mathrm{H}_{0}$ 1: There is no significant influence of siblings' rivalry on antisocial behaviour among secondary school students.

$\mathrm{H}_{0}$ 2: There is no significant influence of parental in-fighting on antisocial behaviour among secondary school students.

\section{REVIEW OF RELATED LITERATURE}

Social Learning Theory, derived from the work of Albert Bandura, holds that observational learning can occur in relation to three models. These models are presented by Mae (2011) as follows:

1. Live Model- whereby an actual person is demonstrating the desired behaviour.

2. Verbal instruction - whereby an individual describes the desired behaviour in detail, and instructs the participants to know how to engage in the behaviour.

3. Symbolic - whereby modelling occurs by means of the media, including, movies, television, internet, literature and radio. This type of modelling involves a real or fictional character demonstrating the behaviour.

An important factor of Bandura's social learning theory is the emphasis on reciprocal determinism. This notion states that an individual behaviour is both influenced by the environment and characteristics of the person. In other words, a person's behaviour, environment and personal qualities all reciprocally influence each other. The result of Bandura's studies provided support for the influence of modelling on learning antisocial behaviours such as fighting in the class, stealing, lying, abusing teachers, and truancy. Further, a later study in 
1965 showed that witnessing the model being punished for the aggressive behaviour decreased the likelihood that children would imitate the behaviour. At this point, it would be useful to view on the fact that the laissezfaire attitude given to this adolescent antisocial behaviour such as sibling rivalry and the widespread incidence of parental infighting has made the adolescent to reproduce similar behaviour in their day-to-day living.

Banduras theory, among other things, explains the negative influence of exposing children to violence, especially in the home setting. On the other hand, this theory is of great significance because observation learning with respect to parental infighting may greatly influence adolescents' behaviour. Just how this influence plays out among adolescents in rapidly urbanized societies like Aba in Abia State of south East Nigeria has not been well understood, hence this study.

Muhammad, Rashida, Riffat and Fayyaz (2011) investigated the impact of siblings' rivalry on students' antisocial behaviour in high schools in Punjab and Paki. The study delimited its scope to two indicators of attitude and behaviour. The population of the study comprised all secondary and higher secondary school teachers and students, a total of 288 schools. Twenty students and ten teachers from each school were randomly selected as the sample of the study. A total of 2460 teachers and 4860 students participated in the study. The data were analysed using Cronbach's Alpha reliability coefficient to check the reliability of the questionnaires and the value was 856. Pearson product correlation coefficient and stepwise Regression Analysis with linear function were used to determine the different impact of siblings' rivalry on students' antisocial behaviour, students who engage in rivalry with their siblings and that of the students with less occurrence rivalry with their siblings.

\section{RESEARCH METHOD}

Design of the Study: This study employed the ex-post facto survey design. This design was considered appropriate for the research as it attempts to check the already existing influence of the independent variables on the dependent variable. The independent variable(s) in ex-post facto survey design cannot be manipulated because of their nature or the fact that the consequences have already been experienced before the researcher gets involved.

Area of the Study: The area of this study was Aba Education Zone, Abia State. Aba Education Zone covers nine Local Government areas namely: Aba North, Aba South, Isiala Ngwa North, Isiala Ngwa South, Ukwa East, Ukwa West, Obingwa, Ugwunagbo and Osisioma. Aba people are predominantly Christians but there are quite a handful of Muslims and pagans. Educationally, there are ninety-two (92) government secondary schools, one hundred and two (102) primary schools in this Zone. The decision to use Aba zone as the area of study for the present study was necessitated by the population of senior secondary students in the education zone which was large enough to provide adequate sample for the study and also form basis for generalization of the finding to a wider population.

Population of the Study: The Population of the study comprised all the senior secondary school students in Aba education zone. The students are 5, 605 for 2013/2014 session (Abia State Secondary School management Board, 2014). This population is considered appropriate because these students aged 12-18 years are able to give objective self-report on their experiences at home and in school.

Sampling: Kline (2005) stated that increase in the sample size will make any result statistically significant. Therefore, the multi-stage random sampling procedure was used to select 1400 adolescents $(25 \%$ of the population) a sample for the study. Conducting a multi-stage random sampling was necessitated by the fact that the researcher cannot select the entire sample at once. Using multi-stage random sampling technique, 30 schools were selected from the 92 existing schools in Aba education zone. The researcher rather had to employ the simple random sampling method at each of the schools selected for the study.

Instrumentation: The instrument used in data collection was the researcher-made questionnaire tagged "Domestic Abuse and Antisocial Behaviour Questionnaire (DAABQ)". The instrument has two sections, Section A and Section B. Section A contains items on examining students' antisocial behaviour while Section B contains items collected data on sibling rivalry and parental infighting. Scoring of the instrument was done on a 4-point scale. The scale has four (4) response categories with four points weight, of SA (Strongly Agree), 4 points, A (Agree) 3 points weight, D (Disagree) 2 points weight, and SD (Strongly Disagree) 1 point. The instrument was validated by one expert in measurement and evaluation and two experts in Educational Psychology. Furthermore, the reliability test for the instrument yielded a Cronbach's alpha coefficient of .862.

Method of Data Analysis: Data collected from the respondents was scored using the weights on scale 4-point scale. Afterwards, the scores on each variable for each respondent were analysed. Descriptive statistics and 
charts were used in answering research questions while the independent student t-test was employed in the hypotheses testing. The independent variables were used as grouping variable and the grouping was done based on the students' scores on each subscale, that is each variable.

\section{RESULTS}

Research Question 1: What is the influence of siblings' rivalry on antisocial behaviour among secondary school students?

Table 1: Weighted mean scores of students' antisocial behaviour due to siblings' rivalry

\begin{tabular}{|l|c|c|}
\hline Siblings' Rivalry & No. of Respondents & Antisocial Behaviour Mean Score \\
\hline High siblings' rivalry & 232 & 39.86 \\
\hline Low siblings' rivalry & 1168 & 27.68 \\
\hline
\end{tabular}

The result presented in Table 1 shows that the mean 39.86 for the students who experienced more sibling rivalry was greater than the antisocial behaviour mean score of 27.68 for the students who reported lesser sibling rivalry. The answer to Research Question 1 therefore is given that sibling rivalry increases the likelihood for adolescents to manifest antisocial behaviour in Aba Education Zone, Abia State.

Research Question 2: What is the influence of parental infighting on antisocial behaviour among secondary school students?

Table 2: Weighted mean scores of students' antisocial behaviour due to parental in-fighting

\begin{tabular}{|l|c|c|}
\hline Parental Infighting & No. of Respondents & Antisocial Behaviour Mean Score \\
\hline High Parental Infighting & 128 & 36.41 \\
\hline Low Parental Infighting & 1272 & 29.02 \\
\hline
\end{tabular}

The result presented in Table 2 shows that students whose parents fought more tended to manifest more antisocial behaviour than those who reported less parental infighting. The mean scores on Table 4 reveals that students who reported more parental infighting scored an average of 36.41 on the antisocial behaviour scale whereas those who reported less parental infighting scored an average of 29.02 on the antisocial behaviour scale. The answer provided by this descriptive statistics to Research Question 4 is that parental infighting has a negative influence on students' social behaviour and tends to increase antisocial behaviour among students in the study region.

Hypothesis 1: There is no significant influence of siblings' rivalry on antisocial behaviour among secondary school students.

Table 3: t-test analysis of sibling's rivalry and antisocial behaviour

\begin{tabular}{|l|l|l|l|l|l|l|l|}
\hline Dependent variable & Siblings' rivalry & & $\bar{\chi}$ & SD & t-calc. & df & p-value \\
\hline Antisocial behaviour & High & 232 & 9.86 & .779 & 21.14 & 1398 & $.000^{*}$ \\
\cline { 2 - 9 } & Low & 168 & 7.68 & .065 & & & \\
\hline
\end{tabular}

*Significant at $p \leq .05 ; \mathrm{t}$-critical $=1.96$

The analysis in Table 3 shows that the p-value is less than the alpha value at 1398 degrees of freedom. Based on this result, Hypothesis 1 which postulated that there is no significant influence of siblings' rivalry on antisocial behaviour among secondary school students was rejected. This shows that sibling's rivalry has a significant influence on antisocial behaviour among secondary school students. Apparently, secondary school students who are frequently involved in brawls, squabbles, and other mischievous outbursts with their siblings at home may naturally transfer this antisocial disposition to the school environment. Hence, the analysis reveals that the mean antisocial behaviour scores of students with more sibling rivalry index was greater than that of students with less sibling rivalry index. This difference gives significant evidence to conclude that sibling rivalry has a negative influence on the antisocial behaviour of students in secondary schools.

Hypothesis 2: There is no significant influence of parental infighting on antisocial behaviour among secondary school students.

Table 4: t-test analysis of parental infighting and antisocial behaviour

\begin{tabular}{|l|l|l|l|l|l|l|l|}
\hline $\begin{array}{l}\text { Dependent } \\
\text { variable }\end{array}$ & $\begin{array}{l}\text { Parental } \\
\text { infighting }\end{array}$ & $\mathrm{N}$ & $\bar{\chi}$ & SD & t-calc. & df & p-value \\
\hline \multirow{2}{*}{ Antisocial behaviour } & High & 128 & 36.41 & 8.123 & 8.899 & 1398 & $.000^{*}$ \\
\cline { 2 - 8 } & Low & 1272 & 29.02 & 9.041 & & & \\
\hline
\end{tabular}

*Significant at $p \leq .05 ; \mathrm{t}$-critical $=1.96$ 
It would be observed from the analysis in Table 4 that the p-value is less than the alpha value at 1398 degrees of freedom. Based on this result, Hypothesis 2 which postulated that there is no significant influence of parental in-fighting on antisocial behaviour among secondary school students was rejected. The analysis provides significant evidence to conclude that parental infighting contributes to antisocial behaviour among secondary school students in the study region. Arguably, children who observe their parents fighting, each time disagreements arise, may adopt violent physical attacks as a way of expressing anger and ill emotions while at school.

\section{DISCUSSION OF THE FINDINGS}

The first specific purpose of this study was to find out the influence of siblings' rivalry on antisocial behaviour among secondary school students. The question this raised for the study was what is the influence of siblings' rivalry on antisocial behaviour among secondary school students? The finding of this study was that secondary school students who experienced more sibling rivalry manifested more antisocial behaviour than secondary school students who experienced less rivalry from their siblings. Statistical test of the first hypothesis gave significant evidence to conclude that siblings' rivalry contributes to the development of antisocial behaviour among secondary school students. This finding is similar to that of Rashida, Riffat and Fayyaz (2011) who found in their study population a significant relationship between sibling rivalry and antisocial behaviour. Obviously, the influence of siblings' rivalry on antisocial behaviour shown in this work could be as a result of the stress and anxiety caused by the prevalence of internecine squabbles between siblings which are usually taken out on peers at school. This agrees with the findings of Keinedy-Moore and Katayama (2007) and Donna (2004) who reported from their separate studies that sibling rivalry often influences the child negatively, causing them to be involved in antisocial behaviour in schools and manifest other social problems. In summary, it is worthy of note that siblings' rivalry which is often dismissed as a normal event in the life of children could result in undesirable social problems and antisocial behaviour.

On the influence of parental infighting on antisocial behaviour among secondary school students, data collected from the sample surveyed was analysed and the result showed that students whose parents fought more frequently manifested more antisocial behaviour than students whose parents did not fight. The observed difference in the antisocial behaviour of these two group of students was statistically significant. Hence, this study found that parental infighting contributed to the increase in antisocial behaviour among secondary school students. This finding is similar to that of Dan (2003) who found in his population that parental infighting had a destructive psychological influence leading to mental health problems and poor academic performance. Other authors, such as Denilson (2002), Howards (2003), Zomitsky and Martin (2006) found in their separate studies significant associations between parental infighting and various antisocial behaviour including anxiety, depression, sleeping during lessons, temper tantrums, and bullying. Arguably, these students transfer the violent eruptions they experience at home to the school and use it against their peers. They may come to see violent confrontations as a way of conflict resolution and means to gain dominance over other students. Whatever the case may be, the issue of parental infighting has been found to contribute to the increase of antisocial behaviour among secondary schools and requires timely intervention as endeavoured by this study.

\section{CONCLUSION}

The findings of this study have exposed the influence of siblings' rivalry and parental infighting on antisocial behaviour among secondary school students. Statistical analysis of data collected on siblings' rivalry and antisocial behaviour revealed that students who experienced rivalry with their siblings at home often get involved in violent confrontations at school, bullying, fighting and other forms of antisocial behaviour. Obviously, these students transfer this behaviour from the home to other social environments.

This study also observed that parental infighting also inculcated in these students the tendency to fight with peers and their seniors. This often leads to incessant cases of fracas at school among students. Based on these empirical inferences, it could be concluded that siblings' rivalry and parental infighting are among the chaotic home climate variables that contribute significantly to the antisocial behaviour of secondary school adolescents in Aba Education Zone in Abia State, Nigeria

\section{RECOMMENDATIONS}

1. Based on the findings of the study, it is recommended that educational psychologists work closely with school counsellors and teachers to identify students who are from chaotic home backgrounds and assist them to overcome the abuse and adjust sufficiently in order to benefit from their secondary school education.

2. Parents should stop fighting themselves especially in the presence of their children rather they should learn to settle their misunderstanding without involving their children. 
3. Parents should show equal love, care and attention to their children to minimize the high rate of survival of the fittest, hatred and segregation among siblings.

4. Parents should from time to time, organize discussion session in the family where the issues affecting members of the family will be discussed. This would forestall sibling rivalry.

5. This study also recommends that parents should identify the individual differences in their children and learn how to treat each of them according to their nature.

6. Parents should improve their education, social and spiritual awareness as this will help to improve their knowledge about child rearing.

7. The government should further ensure the rule of law in order to instil discipline in the society by punishing students who display unruly and antisocial behaviour.

8. Children should learn how to care, share and respect the opinion of their siblings to avoid constant quarrel and rivalry.

\section{REFERENCES}

[1] Caspi, A, McClay J, Moffitt TE, Mill J, Martin J, Craig I. W. (2002). Role of genotype of violence in maltreated children. Science 2002; 297: $851-854$

[2] Denilson, D. (2002). Primary prevention of child physical abuse and neglect: Gaps and promising directions. Child Maltreatment, $12,364-377$.

[3] Dunn, S. M., Bandy, K. P. (2000). Volume-controlled ventilation. In: S. K. Sinha, S. M. Donn (Eds.) Manual neonatal respiratory care. Futura Publishing, Armonk, NY: 153.

[4] Donna, Z. P. (2004). Predictors of resilience in abused and neglected children grown-up: The role of individual and neighbourhood characteristics. Child Abuse and Neglect, 31, 255-274.

[5] Howards, E. (2003). The extent of family violence in Europe. Violence Against Women, 10 (7), 749-769.

[6] Katayama, M., Aoki, E., Suzuki, H., Kawana, S. (2007). Foot shock stress prolongs the telogen stage of the spontaneous hair cycle in a non-depilated mouse model. Exp. Dermatol, 16: $553-560$.

[7] Kline, R. B. (2005). Principles and practice of structural equation modelling. 2nd ed. New York.

[8] Mae-Sincero, S. (2011). What is social learning theory? Retrieved 13 February 2012 from http://www.experimentresources.com/social-learning-theory.html.

[9] Muhammad, Y., Rashida, E., Riffat, D., and Fayyaz, K. (2011).Update on child sexual abuse (Issues Paper No. 5). Melbourne: National Child Protection Clearinghouse.

[10] Rashida, A. D., Riffat, T. F., and Fayyaz A. (2011). Impact of the Prior School Environment on Academic Achievement of Students at the Secondary Stage in Punjab (Pakistan).

[11] Wiehe, V.R. (2003). Empathy and narcissism in a sample of child abuse perpetrators and a comparison sample of foster parents. Child Abuse and Neglect, 27, pp. 541-555. 